\title{
LA CIUDAD DE MÉXICO Y SUS FACULTADES EN ASUN- TOS INTERNACIONALES
}

MEXICO CITY AND ITS FACULTIES REGARDING INTERNATIONAL AFFAIRS

MANUEL BECERRA RAMÍREZ

Resumen: Aún antes de que se hablara del fenómeno de la globalización las entidades estatales, diferentes a las del mismo Estado (municipios, cantones, Estados o provincias, etcétera), realizaban y realizan acuerdos con sus pares a nivel internacional. Esta práctica se ha incrementado en los últimos años, en virtud de la globalización y los fenómenos de integración y posteriormente es retomada por la nueva Constitución de la Ciudad de México (CGM) que entró en vigor el 17 de septiembre de 2018. La CGM forma parte de esa corriente globalizadora e introduce el marco jurídico para que las instancias locales puedan relacionarse y celebrar acuerdos con su entorno internacional. Eso es un gran hito en el constitucionalismo local que aquí comentamos.

Palabras clave: Constitución de la Ciudad de México, acuerdos interinstitucionales, fuentes de derecho internacional, constituciones locales y acuerdos internacionales.

Aвstract: Even before the phenomenon of globalization was discussed, state entities, different from those of the same State (municipalities, cantons, States or provinces, etc.), made and make agreements with their peers at an international level. By virtue of globalization and the phenomena of integration, this practice has increased in recent years, and is subsequently taken up by the new Constitution of Mexico City (CGM), which entered into force on September 17, 2018. The GCM is part of this globalizing trend and introduces the legal framework so that local authorities can relate and celebrate agreements with their peers in the international arena. That is a great milestone in the local constitutionalism and that we discuss here.

${ }^{1}$ Investigador del Instituto de Investigaciones Jurídicas de la UNAM y Director del "Anuario Mexicano de Derecho Internacional".<manuelbramirez5@hotmail. com>. ORCID: https://orcid.org/0000-0003-3957-9446

Fecha de recepción: 17 de mayo de 2019; fecha de aprobación: 26 de septiembre de 2019. 
Keywords: Constitution of Mexico City, interinstitutional agreements, sources of international law, local constitutions and international agreements.

Sumario: I. Introducción; II. Auge de los AI; III. Marco constitucional-legal mexicano; IV. La experiencia internacional. El caso de la Constitución de Buenos Aires; V. La Constitución de la Ciudad de México y su artículo 20; VI. La impugnación del artículo 20 de la CCM y la sentencia de la SCJN; VII. Conclusiones; VIII. Fuentes.

\section{INTRODUCCIÓN}

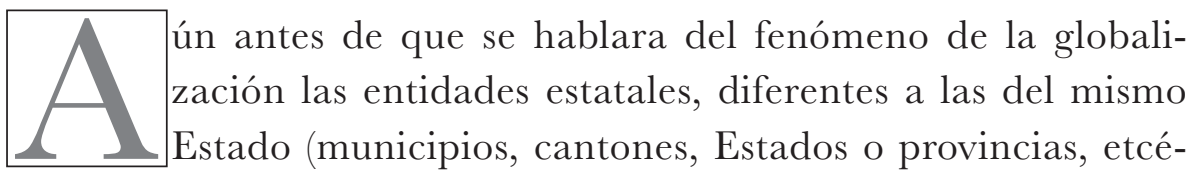
tera), realizaban y realizan acuerdos con sus pares a nivel internacional. Tradicionalmente por necesidades de su situación geográfica, por ejemplo, las entidades fronterizas tenían que realizar acuerdos con sus pares del otro lado de la frontera sobre cuestiones de tránsito comercial, vehicular, medio ambiente y demás asuntos, necesarios para la convivencia vecinal. En México a esos acuerdos se les denominaba convenios ejecutivos ${ }^{2}$.

Por otra parte, en un momento en que en que nuestro país intentaba insertarse en el fenómeno de la globalización, cuando ya se negociaba el Tratado de Libre Comercio de América del Norte, fue aprobado por el legislativo, la Ley de Celebración de Tratados de 1992 (LCT), a esos acuerdos se les denominó acuerdos interinstitucionales (AI).

En la doctrina de derecho internacional los AI son objeto de cierta polémica pues algunos consideran, con mucha razón, que estos fenómenos jurídicos no están regulados por el derecho internacional pues sus sujetos no están reconocidos por la subjetividad internacional. Sin embargo, se considera que son actos necesarios.

\footnotetext{
${ }^{2}$ Véase: Bernal, Carlos, "Los convenios ejecutivos ante el derecho constitucional e internacional", Jurídica; México, núm. 12, 1980.
} 
En los últimos años, fundamentalmente dos fenómenos han influido al auge de estos AI celebrados por las instancias diferentes a las estatales: La globalización y fenómenos de integración han intensificado la actividad de las instancias no estatales a nivel internacional: acuerdos internacionales con sus pares e inclusive con Organismos Internacionales $(\mathrm{OI})^{3}$.

La nueva Constitución de la Ciudad de México que entró en vigor el 17 de septiembre de 2018 forma parte de esa corriente globalizadora e introduce el marco jurídico para que las instancias locales puedan relacionarse y celebrar acuerdos con su entorno internacional. Eso es un gran hito en el constitucionalismo local que aquí comentamos.

Otra cuestión interesante, que comentaremos es la resolución de la Suprema Corte de Justicia de la Nación (SCJN) en relación con los acuerdos que el gobierno de la ciudad de México puede realizar.

II. Auge de los al

En las últimas décadas, como ya mencionamos, la llamada globalización y después la integración, son los dos fenómenos que ha intensificado la actividad de las instancias no estatales a nivel internacional con acuerdos internacionales con sus pares e inclusive con Organismos Internacionales (OIs). Los estudiosos del tema ya han observado como con estos AI, se rompe el paradigma del Estado como único titular de la subjetividad estatal, aunque la conservadora doctrina de derecho internacional no se pronuncia por reconocer que este tipo de acuerdos soy ya una nueva fuente de derecho internacional.

Por su parte, desde la disciplina de las relaciones internacionales, Paulino Arellanes estudioso de estos fenómenos locales que se pro-

\footnotetext{
${ }^{3}$ Arellanes Jiménez, Paulino, Los gobiernos locales de Europa y sus relaciones internacionales, Gernika, México, 2014, pp.8-11.
} 
yectan a nivel internacional, cita 5 causas del auge o incremento de las relaciones internacionales de los gobiernos locales, a partir de cambios en el mundo:

"1. Por un lado, el fenómeno de la globalización subrayó la importancia de las interconexiones mundiales y planteó nuevas relaciones entre los procesos internacionales y domésticos.

"Las ciudades, como principales nódulos de relación, intercambio y producción, constituyen en la actualidad el lugar donde se asientan y se desarrollan las economías globalizadas"

2. "...el desarrollo del sistema económico global requiere de un espacio organizativo y social, capaz de brindar una serie de actividades y servicios especializados. El 'lugar/territorio' preferencial para la producción de esos requerimientos de la globalización son las ciudades" 3. "las regiones y ciudades ya no tienen un horizonte prefijado, ni establecido centralmente, sino que deben ser gestoras de su propio desarrollo. El territorio subnacional-en cualquiera de sus niveles-se convierte en el nuevo actor del desarrollo.

4. ...el avance de los procesos de integración regional hace que las políticas urbanas no se satisfagan más con una visión de la gestión limitada a las fronteras locales o nacionales."

"... existen varios conceptos por medio de los cuales se nombran los procesos en los que se han involucrado "otros actores" que no son precisamente los estados-nación así tenemos paradiplomacia, gobiernos subnacionales, cooperación descentralizada y trabajo en red; que aunque cada término es utilizado con sus propias características y a su vez adecuado a cada realidad dentro de los Estados-nación, consideramos que el concepto de gobiernos locales engloba a los anteriores, ya que tanto paradiplomacia como cooperación descentralizada son mecanismo y estrategias que los gobiernos locales utilizan en sus relaciones internacionales"

5. Las agencias-y en particular la UE-comenzaron a tomar conciencia del papel activo que las ciudades y sus comunidades pueden tener en la cooperación internacional, no ya como simples beneficiarios sino como actores protagónicos de las iniciativas"4

\section{${ }^{4}$ Ibidem.}


De acuerdo con lo señalado por Paulino Arellanes nos hace pensar que al volcarse las entidades no estatales a la arena internacional hay un impacto en el diseño de las instituciones del Estados, como, por ejemplo, surge la necesidad de crear una para-diplomacia y una estructura administrativa necesarias para su gestión; independientemente de la urgencia en adecuar el derecho, para crear un sistema de pesos y contrapesos y una revisión de la relación con el ente estatal al que pertenecen.

\section{ill. Marco constitucional-legal mexicano}

Ahora bien, ¿en dónde están situadas las actividades internacionales de estos "gobiernos locales"? En principio, analizando desde el más alto ordenamiento legal mexicano, la Constitución de 1917, siguiendo a sus similares, toma a los tratados como el centro de su sistema de recepción del derecho internacional. En efecto, la Constitución es muy clara cuando establece:

Artículo 117. Los Estados no pueden, en ningún caso:

I. Celebrar alianza, tratado o coalición con otro Estado ni con las

Potencias extranjeras;

Esta es una regla contundente, pues el sistema adoptado por la Constitución consiste en darle al poder ejecutivo la facultad de realizar tratados internacionales, con el contrapeso de la Cámara de Senadores. Ahora bien, este principio se complementa con la fórmula de recepción del derecho internacional, contenida en el artículo 133 de la Constitución de $1917^{5}$ De esta manera, la Cons-

${ }^{5}$ Artículo 133. Esta Constitución, las leyes del Congreso de la Unión que emanen de ella y todos los Tratados que estén de acuerdo con la misma, celebrados y que se celebren por el Presidente de la República, con aprobación del Senado, serán la Ley Suprema de toda la Unión. Los jueces de cada Estado se arreglarán a dicha Constitución, leyes y tratados, a pesar de las disposiciones en contrario que pueda haber en las Constituciones o leyes de los Estados. D.O.F. 15-05-2019, Constitución Política de los Estados Unidos Mexicanos de 1917. 
titución establece un sistema de celebración de los tratados internacionales, en donde hay un sistema de pesos y contrapesos con la participación de los tres poderes de la federación. ${ }^{6}$

Además, el Presidente tiene facultades para dirigir la política exterior que debe ceñirse a los principios que señala la Constitución en su artículo 89-X y celebrar tratados internacionales, así como terminar, denunciar, suspender, modificar, enmendar, retirar reservas y formular declaraciones interpretativas sobre los mismos. Para nuestro tema, uno de los principios de la política exterior es "la cooperación internacional para el desarrollo". El contrapeso, como vimos, se encuentra en el Senado que debe de aprobar a los tratados internacionales ${ }^{7}$. El control que ejerce el poder judicial está contenido en varios artículos de la Constitución (artículo 104-II; 105-II 107 fracción VIII) y en forma sobresaliente en el artículo 133.

Ahora bien, el marco de la Constitución mexicana se completa con lo dispuesto en su artículo 40 que remite a la soberanía popular, "Es voluntad del pueblo mexicano constituirse en una República representativa, democrática, laica y federal, compuesta por Estados libres y soberanos en todo lo concerniente a su régimen interior,

${ }^{6}$ Concretamente, los contrapesos son: que los tratados estén de acuerdo con la Constitución; que se celebren por el Presidente de la República, con aprobación del Senado. Esta cámara del poder legislativo se erige como un órgano del Estados con la gran facultad, y que implica responsabilidad, de servir como un contrapeso a la facultad del ejecutivo de celebrar tratados, en otras palabras, de comprometer a México en asuntos internacionales. Además, otra vigilancia está en el artículo 15 de la misma Constitución que establece un control sobre el contenido de los tratados en materia de derechos humanos: "No se autoriza la celebración de tratados para la extradición de reos políticos, ni para la de aquellos delincuentes del orden común que hayan tenido en el país donde cometieron el delito, la condición de esclavos; ni de convenios o tratados en virtud de los que se alteren los derechos humanos reconocidos por esta Constitución y en los tratados internacionales de los que el Estado Mexicano sea parte. D.O.F. 15-05-2019, Constitución Política de los Estados Unidos Mexicanos de 1917.

${ }^{7}$ De conformidad con la fracción I del artículo 76 de la Constitución Política de los Estados Unidos Mexicanos, los tratados deberán ser aprobados por el Senado, lo que reitera la disposición del artículo 133 de la propia Constitución. D.O.F. 15-05-2019, Constitución Política de los Estados Unidos Mexicanos de 1917. 
y por la Ciudad de México, unidos en una federación establecida según los principios de esta ley fundamental". Y en ese sentido, de acuerdo con su artículo 41 "El pueblo ejerce su soberanía por medio de los Poderes de la Unión, en los casos de la competencia de éstos, y por los de los Estados y la Ciudad de México, en lo que toca a sus regímenes interiores, en los términos respectivamente establecidos por la presente Constitución Federal y las particulares de cada Estado y de la Ciudad de México, las que en ningún caso podrán contravenir las estipulaciones del Pacto Federal".

Como vimos, parte de las prohibiciones las encontramos en el mencionado artículo 117 en donde se encuentra clara la prohibición para los Estado de la Federación mexicana de celebrar tratados internacionales. Eso significa que la soberanía popular ha querido establecer que sólo el Estado puede realizar tratados. En consecuencia, de acuerdo con la Constitución, los acuerdos interinstitucionales no serán ni deberán ser tratados internacionales, será otra figura jurídica a nivel interno.

Por otra parte, también la Constitución, en su artículo 122, se refiere a la Ciudad de México, estableciéndose que "es una entidad federativa que goza de autonomía en todo lo concerniente a su régimen interior y a su organización política y administrativa”. En cuanto a sus facultades, y aquí entenderíamos las facultades de la Ciudad de México para celebrar acuerdos interinstitucionales, son de carácter "remanentes" de acuerdo con lo dispuesto en el artículo $124^{8}$

Sin embargo, y volviendo con el tema de los acuerdos interinstitucionales, el nivel de acuerdos que celebran las instancias no estatales no cae en la categoría de tratados, sino de otro tipo de acuerdo, como dijimos anteriormente, regulados por la Ley Sobre

${ }^{8}$ Artículo 124 de la Constitución. Las facultades que no están expresamente concedidas por esta Constitución a los funcionarios federales se entienden reservadas a los Estados o a la Ciudad de México, en los ámbitos de sus respectivas competencias. D.O.F. 15-05-2019, Constitución Política de los Estados Unidos Mexicanos de 1917. 
la Celebración de Tratados de 1992 (LSCT). Para plantear el tema, vemos que dice la ley sobe los acuerdos interinstitucionales; en principio, la LSCT, establece:

Artículo 2o.- Para los efectos de la presente Ley se entenderá por: II.- "Acuerdo Interinstitucional": el convenio regido por el derecho internacional público, celebrado por escrito entre cualquier dependencia u organismo descentralizado de la Administración Pública Federal, Estatal o Municipal y uno o varios órganos gubernamentales extranjeros u organizaciones internacionales, cualquiera que sea su denominación, sea que derive o no de un tratado previamente aprobado. El ámbito material de los acuerdos interinstitucionales deberá circunscribirse exclusivamente a las atribuciones propias de las dependencias y organismos descentralizados de los niveles de gobierno mencionados que los suscriben.

Esta figura de AI es muy criticada en la doctrina, por su falta de fundamento constitucional. ${ }^{9}$ Sin embargo, actualmente parecería que ella es la única que le podría dar sostén jurídico a los innumerables acuerdos internacionales que celebra el gobierno de la Ciudad de México. Ahora bien, surge la pregunta teórica-técnica constitucional: si los AI que la federación reconoce no tiene un soporte constitucional, (insistimos, según una parte importante de la doctrina); ¿es posible insertarlos en la Constitución de la CDMEX?.

La respuesta a esta cuestión sería que sí, pues la Constitución federal toma como regla para la distribución de las competencias entre la federación y los Estados que la componen: "la competencia residual", es decir todo aquello que no esté expresamente concedi-

\footnotetext{
${ }^{9}$ Véase: Cruz Miramontes, "El tratado de Libre Comercio de América del Norte y las Denominadas 'Cartas paralelas', Anuario Mexicano de Derecho Internacional, México, vol. I, 2001; Méndez Silva, Ricardo, "La celebración de los tratados genealogía y actualidad constitucional", Anuario Mexicano de Derecho Internacional, México, vol. I, 2001; Becerra Ramírez, Manuel, La recepción del derecho internacional en derecho interno, Instituto de Investigaciones Jurídicas, UNAM, México, segunda edición.
} 
da a la Federación corresponde a los Estados ${ }^{10}$.

Ahora bien, independientemente de su actividad de gestión natural y de su impulso a realizar actos internacionales por su inserción en la globalización, la Ciudad de México, tiene la obligación de cumplir con una serie de compromisos internacionales derivados de su pertenencia al Estado mexicano. En efecto, esos compromisos tienen que ver, entre otros, con:

- El cumplimiento de tratados en los límites de su competencia;

- El cumplimiento de sentencias internacionales; por ejemplo, a la CDMEX le toca una parte de obligaciones en las sentencias que dicte la Corte Interamericana de Derechos Humanos. Es más, el control de convencionalidad es una obligación que llega hasta los tribunales locales;

- El cumplimiento de las obligaciones internacionales derivadas de otras fuentes del derecho internacional (costumbre, resolución de los organismos internacionales, por ejemplo).

En ese sentido, es necesario tener un esquema de recepción del derecho internacional adecuado para lo que es una entidad no estatal estrictamente hablando. Sabemos que el sistema de recepción del derecho internacional de la Constitución mexicana de 1917 es incompleto $^{11}$. Por eso, era una muy buena oportunidad para que la Constitución de la CDMEX pudiera subsanar la deficiencia del sistema mexicano de recepción, con normas que, con un sistema de pesos y contrapesos, pueda permitirle a la ciudad su sano y normal contacto internacional. En tal virtud, era interesante ver cuál era el resultado del constituyente local cuando se diseñó la Constitución de la Ciudad de México. A eso nos referimos más adelante.

${ }^{10}$ Véase el artículo 124 de la Constitución. D.O.F. 15-05-2019, Constitución Política de los Estados Unidos Mexicanos de 1917.

${ }^{11}$ Véase Beccerra Ramírez, Manuel, La recepción del derecho internacional en derecho interno, Op. cit. 
IV. LA EXPERIENCIA INTERNACIONAL. El CASO DE LA CONSTITUCIÓN DE BUENOS AIRES

En América Latina, el otorgamiento constitucional a las entidades estrictamente no estatales es una corriente importante ${ }^{12}$. Aquí traemos a colación dos ejemplos. En principio, la Constitución Ecuatoriana de 2008, hace una división en materia de competencia, entre las que le son atribuidas al Estado central ${ }^{13}$ y la que le son atribuidas, en principio a los gobiernos regionales autónomos y después a los gobiernos provinciales y municipales, a los cuales se les otorga, entre otras, la competencia para "gestionar la cooperación internacional para el cumplimiento de sus competencias" ${ }^{14}$, e inclusive también esa facultad se le otorga a los gobiernos parroquiales rurales ${ }^{15}$.

El otro ejemplo es la Constitución de Buenos Aires, y en forma concreta la Ciudad de Buenos Aires que tiene gran similitud, en términos de organización, con la Ciudad de México. Ambas ciudades son sedes del gobierno federal al ser la capital de su propio país, por lo que las relaciones entre ambos niveles de gobierno varían dependiendo de la materia. Por esta razón muchas de sus funciones son realizadas en cooperación con las autoridades federales, o incluso éstas pueden llegar a sustituir a los órganos de las ciudades autónomas.

De la misma manera que la Ciudad de México, la Ciudad Autónoma de Buenos Aires, tiene una autonomía política, administrativa y económica; sus competencias son residuales de aquellas que la

${ }^{12}$ Véase: Sánchez, Reyes, Wendy, ¿Los acuerdos interinstitucionales, constituyen una fuerte de derecho internacional en el siglo XXI?, Tesis de licenciatura, Facultad de Derecho de la Universidad Nacional Autónoma de México, México, 2018.

${ }^{13}$ Constitución Ecuatoriana artículo 261.

${ }^{14}$ Constitución Ecuatoriana, artículos 262-9; 263-8; 264-14.

${ }^{15}$ Constitución Ecuatoriana, Artículo 267-7. 
Constitución Nacional confiere al Gobierno Federal y algunas de ellas son concurrentes: derechos humanos, seguridad pública, etc. Pero al parecer se mantiene la preeminencia en las competencias de lo federal sobre lo local, igualmente que en México se trata de un federalismo centralizado.

En materia internacional la Constitución Nacional de Argentina prohíbe que la Ciudad de Buenos Aires, así como las provincias, celebren cualquier tratado de carácter político; ${ }^{16}$ sin embargo, están plenamente facultadas para celebrar tratados parciales en materia de administración de justicia, intereses económicos y trabajos de utilidad común, siempre y cuando tengan el aval del Congreso Nacional $^{17}$. Es en materia de desarrollo económico y social donde las provincias adquieren mayor capacidad internacional ya que "podrán también celebrar convenios internacionales en tanto no sean incompatibles con la política exterior de la Nación y no afecten las facultades delegadas al Gobierno Federal o el crédito público de la Nación; con conocimiento del Congreso Nacional"18.

La propia constitución local confirma la capacidad de la Ciudad de Buenos Aires para realizar acuerdos internacionales en materia de "ingresos" entre otros, especificando que éstos pueden celebrarse con la propia Nación, las Provincias, las regiones o las municipalidades, pero sobre todo con los Estados extranjeros y los organismos internacionales.

La Constitución de la Ciudad Autónoma de Buenos Aires (CCABA) fue aprobada por la Convención Constituyente de la Ciudad de Buenos Aires, el primero de octubre del año de 1996. En principio, parte de fuertes facultades de autodeterminación local e inclusive a nivel internacional. Aunque su diseño es de una división de po-

\footnotetext{
${ }^{16}$ Artículo 126 de la Constitución Política de la Nación Argentina.

${ }^{17}$ Artículo 125 de la Constitución Política de la Nación Argentina.

${ }^{18}$ Artículo 124 de la Constitución Política de la Nación Argentina.
} 
deres que funcionan contrapesándose ente ellos, las facultades más importantes en asuntos internacionales están en el ejecutivo local.

Dentro de un régimen federal, la CCABA le da una fuerte autodeterminación local a la Ciudad Autónoma de Buenos Aires (CABA). A tal grado que supeditan las obligaciones contraídas por la federación a la conformidad con la constitución local:

"Las obligaciones contraídas por una intervención federal solo obligan a la Ciudad cuando su fuente sean actos jurídicos conforme a esta Constitución y a las leyes de la Ciudad"19.

Aunque no se menciona, se entendería que en la expresión "Las obligaciones contraídas por una intervención federal”, se comprende, por su amplitud, también a los tratados internacionales.

En lo que se refiere a la recepción del derecho internacional, la CCABA hace varias referencias al derecho internacional (DI), lo que es adecuado en cuanto que el concepto "derecho internacional" es amplio incluye todas las fuentes de esa disciplina jurídica. Como se ve a continuación:

- Así se refiere al DI cuando se trata de los límites territoriales de la $\mathrm{CABA}^{20}$

- O bien en materia de seguridad se remite a lo dispuesto por la $\mathrm{ONU}^{21}$;

${ }^{19}$ En efecto, se establece en el: Capitulo primero. Principios. Artículo 5.- Las obligaciones contraídas por una intervención federal solo obligan a la Ciudad cuando su fuente sean actos jurídicos conforme a esta Constitución y a las leyes de la Ciudad. Los magistrados, funcionarios y empleados nombrados por una intervención federal, cesan automáticamente a los sesenta días de asumir las autoridades electas, salvo confirmación o nuevo nombramiento de estas.

${ }^{20}$ Capitulo Segundo. Límites y recursos. Artículo 8.- Los límites territoriales de la Ciudad de Buenos Aires son los que históricamente y por derecho le corresponden. Todo ello sin perjuicio de las normas de derecho internacional aplicables al Río de la Plata y con los alcances del Artículo 129 de la Constitución Nacional .

${ }^{21}$ Capitulo Octavo. Seguridad. Articulo 34.- La seguridad pública es un deber propio e irrenunciable del Estado y es ofrecido con equidad a todos los habitantes.

"El servicio estará a cargo de una policía de seguridad dependiente del Poder Ejecutivo, cuya organización se ajusta a los siguientes principios:

"El comportamiento del personal policial debe responder a las reglas éticas para fun- 
- O en materia de derecho de los trabajadores se remite a los tratados internacionales y a las recomendaciones de la OIT ${ }^{22}$

Por otra parte, la CCABA establece un sistema clásico de división de poderes y de balance entre los tres poderes: legislativo, judicial y ejecutivo ${ }^{23}$. En donde el poder ejecutivo, es decir el Jefe de Gobierno, es el que tiene facultades muy claras y amplias. Con participación de los dos poderes restantes que sirven como contrapeso.

En lo que se refiere a las facultades del Jefe de Gobierno en asuntos internacionales, el Artículo 104 de la CCABA establece sus atribuciones y facultades:

- Concluye y firma los tratados, convenios y acuerdos internacionales e interjurisdiccionales.

- También puede celebrar convenios con entes públicos nacionales, provinciales, municipales y extranjeros y con organismos internacionales, y acuerdos para formar regiones con las Provincias y Municipios, en especial con la Provincia de Buenos Aires y sus municipios respecto del área metropolitana, en todos los casos con aprobación de la Legislatura.

- Fomenta la instalación de sedes y delegaciones de organismos del Mercosur e internacionales en la Ciudad.

- Designa a los representantes de la Ciudad ante los organismos federales, ante todos los entes interjurisdiccionales y de regulación y control de los servicios cuya prestación se lleva a cabo de manera interjurisdiccional e interconectada, y ante los internacionales en que participa la Ciudad..."

cionarios encargados de hacer cumplir la ley, establecidas por la Organización de las Naciones Unidas (el énfasis es nuestro).

${ }^{22}$ Capitulo Decimocuarto. Trabajo Y Seguridad Social. Articulo 43.- La Ciudad protege el trabajo en todas sus formas. Asegura al trabajador los derechos establecidos en la Constitución Nacional y se atiene a los convenios ratificados y considera las recomendaciones de la Organización Internacional del Trabajo. La Ciudad provee a la formación profesional y cultural de los trabajadores y procura la observancia de su derecho a la información y consulta.

23 "Artículo 129o.- La Ciudad de Buenos Aires tendrá un régimen de gobierno autónomo, con facultades propias de legislación y Jurisdicción, y su jefe de gobierno será elegido directamente por el pueblo de la ciudad..." Además véase artículos 68, 95 y 106. 
La CCABA permite allegarse de recursos extranjeros vía "acuerdos", su artículo 9 establece:

"Son recursos de la Ciudad Autónoma de Buenos Aires. '....

"11. Los ingresos provenientes de los acuerdos celebrados con la Nación las Provincias, las regiones, las municipalidades, los estados extranjeros y los organismos internacionales".

Además, en el artículo 53 de la misma CCABA se establece que: "Los poderes públicos sólo pueden contraer obligaciones y realizar gastos de acuerdo con la ley de presupuesto y las específicas que a tal efecto se dicten.

"Toda operación de crédito público, interno o externo es autorizada por ley con determinación concreta de su objetivo."

"Todos los actos que impliquen administración de recursos son públicos y se difunden sin restricción. No hay gastos reservados, secretos o análogos, cualquiera sea su denominación".

Es decir, se autoriza a la CABA a realizar empréstitos internacionales en el marco de la ley.

Ahora bien, como medida de control o contrapeso, se le da al Jefe de Gobierno el deber de: "8. Acordar el arreglo de la deuda de la Ciudad y remitir el acuerdo a la Legislatura para su aprobación" (Artículo 105 de la CAABA). Además, se pueden ver contrapesos a las facultades internacionales. En principio, el poder legislativo ${ }^{24}$ (la legislatura de la ciudad), artículo 80-8 de la CCABA): aprueba o rechaza los tratados, convenios y acuerdo celebrados por el Gobernador.

$\mathrm{Y}$ en lo que toca al poder judicial:

"Corresponde al Poder Judicial de la Ciudad el conocimiento y decisión de todas las causas que versen sobre puntos regidos por esta Constitu-

${ }^{24}$ Artículo 68.- El Poder Legislativo es ejercido por una Legislatura compuesta por sesenta diputados o diputadas, cuyo número puede aumentarse en proporción al crecimiento de la población y por ley aprobada por dos tercios de sus miembros, vigente a partir de los dos años de su sanción. 
ción, por los convenios que celebre la Ciudad, por los códigos de fondo y por las leyes y normas nacionales y locales, así como también organizar la mediación voluntaria conforme la ley que la reglamente. Ejerce esta competencia, sin perjuicio del juicio por jurados que la ley establezca"25.

Por último, es interesante notar que como parte de los derechos ciudadanos, la CAABA otorga derecho de voto a los extranjeros y a la ciudadanía en general concede la facultad de referéndum respecto de "reforma o derogación de una norma de alcance general". Pero se excluye del referéndum "las materias excluidas del derecho de iniciativa, los "tratados interjurisdiccionales" y las que requieran mayorías especiales para su aprobación”. Como se nota solo estos tratados están excluidos, eso significa que los demás tratados si pueden ser sometidos a referéndum ${ }^{26}$.

v. La constitución de la Ciudad de México y su artículo 20 El 30 de enero de 2017, fue aprobada la Constitución Política de la Ciudad de México, después de haber sido redactada y discutida por la Asamblea Constituyente de la Ciudad de México y entró en vigor el 17 de septiembre del año de $2018^{27}$. Con este hito, la ciudad deja de ser Distrito Federal.

En lo que respecta a los asuntos internacionales, en su artículo 20, bajo el título de "Ciudad Global" 28, la nueva Constitución es bastante revolucionaria, pero como vimos no novedosa, se suma a la tendencia internacional.

Con el artículo 20 de la CGM se reconoce a la Ciudad de México una vocación internacional, al reconocer sus obligaciones derivadas

${ }^{25}$ Artículo 106 de la CGABA.

${ }^{26}$ Artículo 65 de la CCABA.

${ }^{27}$ DOF 5 de febrero del año 2017.

${ }^{28}$ El artículo 20 de la Constitución Política de la Ciudad de México, denominado "Ciudad Global", establece:

"1. La Ciudad de México reafirma su histórica vocación pacifista, solidaria, hos- 
pitalaria y de asilo.

"2. La Ciudad de México promoverá su presencia en el mundo y su inserción en el sistema global y de redes de ciudades y gobiernos locales, establecerá acuerdos de cooperación técnica con organismos multilaterales, instituciones extranjeras y organizaciones internacionales, de conformidad con las leyes en la materia, y asumirá su corresponsabilidad en la solución de los problemas de la humanidad, bajo los principios que rigen la política exterior.

"3. Las autoridades adoptarán medidas y programas para contribuir al respeto y protección de los derechos, la cultura y la identidad de las personas originarias de la Ciudad y de sus familias en el exterior. Asimismo, establecerán los mecanismos institucionales para garantizar dicha protección, en los ámbitos de su competencia, y para el apoyo en los trámites respectivos. Las autoridades de la Ciudad de México y de las alcaldías, adoptarán las medidas necesarias para prevenir la migración forzosa de las y los habitantes de la Ciudad de México.

“4. El Congreso de la Ciudad de México armonizará su legislación con los tratados de derechos humanos celebrados por el Estado mexicano y la jurisprudencia de los tribunales y órganos internacionales para su cumplimiento.

"5. El Gobierno de la Ciudad de México y todas las autoridades locales, en el ámbito de sus competencias, deberán promover, respetar, proteger y garantizar los derechos humanos de las personas migrantes, ya sea que se encuentren en tránsito, retornen a la Ciudad de México o que éste sea su destino, así como aquellas personas a las que les hubiera reconocido la condición de refugiados u otorgado asilo político o protección complementaria, con especial énfasis en niñas, niños y adolescentes, de conformidad con lo establecido en la Constitución Política de los Estados Unidos Mexicanos, los tratados internacionales y las leyes federales en la materia. El Gobierno de la Ciudad de México, en coordinación con las alcaldías, instrumentará políticas de acogida a favor de las personas migrantes, así como de aquéllas que busquen y reciban asilo y protección internacional en México.

"6. El Gobierno de la Ciudad generará los mecanismos necesarios para reconocer como víctimas de desplazamiento forzado interno a aquellas personas o grupos de personas forzadas u obligadas a escapar o huir de su hogar o de su lugar de residencia, como resultado de situaciones de violencia generalizada, de violaciones de derechos humanos o de catástrofes naturales o provocadas por el ser humano, sin que ello implique que crucen una frontera estatal internacionalmente reconocida. Las autoridades de la Ciudad de México deberán promover, respetar, proteger y garantizar los derechos humanos de todas las personas a quienes se les reconozca como víctimas de desplazamiento forzado interno.

"7. Los poderes públicos, organismos autónomos y alcaldías podrán celebrar acuerdos interinstitucionales con entidades gubernamentales equivalentes de otras naciones y con organizaciones multinacionales, que favorezcan la cooperación internacional y las relaciones de amistad, de conformidad con las leyes en la materia.

"8. Los acuerdos y acciones internacionales del Gobierno de la Ciudad se informarán semestralmente al Congreso de la Ciudad y a las y los ciudadanos. En esos informes será preceptivo evaluar, cuantitativa y cualitativamente, por el gobierno y el Congreso las ventajas y beneficios de los acuerdos de carácter internacional de la Ciudad.

"9. El Gobierno de la Ciudad establecerá un órgano coordinador de asuntos in- 
de los tratados internacionales y dar la posibilidad, en los ámbitos de su competencia, que realice acuerdos internacionales, a partir de los que podemos considerar sus principios en materia internacional: "La ciudad de México tiene ...vocación pacifista, solidaria, hospitalaria y de asilo". Esto es importante pues se retoma una vocación del asilo y refugio a los extranjeros perseguidos que tenía la política exterior de México y que se manifestó en el caso de los españoles con la Guerra Civil española y los perseguidos por las dictaduras sudamericanas en las décadas de los 70s.-80s. del siglo pasado. Además, hay una relación directa y natural con los principios de la política exterior contenidos en el artículo 89-X de la Constitución de 1917.

En el punto 3 se establece una especie de protección diplomática ("Las autoridades adoptarán medidas y programas para contribuir al respeto y protección de los derechos, la cultura y la identidad de las personas originarias de la Ciudad y de sus familias en el exterior”), aunque no es nada claro cómo se puede llevar a la práctica, pues es una obligación que corre a cargo de los consulados y como sabemos cae en la competencia federal.

Lo mismo sucede con la obligación de prevenir, la migración forzosa de los habitantes de la Ciudad de México. ¿Cómo se puede prevenir? Esta misma preocupación de los desplazados internos se retoma en el numeral 6; aun cuando los desplazados no traspasen las fronteras estatales.

Más adelante, en los numerales 4 y 5 de la Constitución se hace referencia a la armonización de la legislación con los tratados de

ternacionales con la participación de actores públicos, privados, organizaciones de la sociedad civil y ciudadanía que mantengan vínculos con el exterior. Asimismo, promoverá la participación de las organizaciones de la sociedad civil en el ámbito internacional.

"10. La Ciudad de México mantendrá relaciones de colaboración con las embajadas, consulados, representaciones de organismos internacionales, cámaras de la industria o del comercio e institutos culturales extranjeros que se encuentren dentro de su territorio a fin de promover la cooperación y el intercambio social y cultural. Constitución Política de la Ciudad de México. 
derechos humanos y a la protección de los derechos humanos, inclusive de las personas migrantes. Lo cual es reiteración de una obligación que se tiene en virtud de lo dispuesto en el artículo 133 de la Constitución de 1917.

Los numerales 7 y 8 se refieren a la celebración de los acuerdos interinstitucionales, como una facultad del Gobierno de la Ciudad y se establece como contrapeso la obligación de informar semestralmente al Congreso de la Ciudad de México y a "las y los ciudadanos"; esa obligación también implica "evaluar, cuantitativa y cualitativamente, por el gobierno y el Congreso las ventajas y beneficios de los acuerdos de carácter internacional de la Ciudad”. Lo que no dice la CGM es si el Congreso y/o los ciudadanos tienen derecho de veto, lo que sería correcto, si no, estamos hablando de un control inocuo. Por eso podemos observar que no cuenta con un sistema de control o de contrapeso claro y es cuestión de ver la ley reglamentaria si repara esta deficiencia.

Más adelante, en el numeral 9, la CCM establece la obligación de crear un órgano coordinador de asuntos internacionales (OCAI), el cual tendrá una composición variada. Toca a la ley reglamentaria establecer sus facultades concretas, su manera de funcionamiento. Así, como esta expresado, es sumamente vago.

Por otra parte, la facultad contenida en el numeral 10 de mantener relaciones de colaboraciones con entes extranjeros (con las embajadas, consulados, representaciones de organismos internacionales, cámaras de la industria o del comercio e institutos culturales extranjeros...), es normal, lo interesante y trascendente para el derecho es cuando se adquiera algún compromiso. En este caso, ¿Quién es el responsable, la Ciudad de México o el Estado como tal?

En realidad, respecto de todos los compromisos internacionales que contraiga la Ciudad de México se puede plantear la pregunta, 
en caso de incumplimiento, ¿quién es el responsable? El actual derecho internacional habla de responsabilidad indivisible del Estado, además de que no reconoce la subjetividad de los órganos internos. Sería impensable que la Corte Internacional de Justicia conociera de una demanda en contra de un Estado de la federación o una provincia de un Estado.

VI. La impugnación del artículo 20 de La CCM y LA SeNTENCIA DE LA SCJN

La Procuraduría General de la República (PGR) impugnó ante la SCJN este artículo 20 de la CGM, porque según ella trasgrede la Constitución en varios de sus artículos (89, fracción X, y 76, fracción I, en relación con el 117, fracción I) que tienen que ver con las facultades otorgadas al Presidente y al Senado para conducir la política exterior y realizar tratados internacionales. La PGR alega que la CGM concede facultades a las autoridades de la Ciudad de México que están originalmente, de acuerdo con el Constituyente de 1917 reservadas al Presidente y al Senado (véase los párrafos 313 al 315).

Después de analizar los argumentos de la PGR y el marco normativo para la celebración de los tratados llega al meollo de la contradicción y establece la cuestión a resolver: si los acuerdos a que se refiere la CGM en su artículo 20-7 y 8 constituyen o no tratados; en caso afirmativo sí se trasgrede la Constitución. Sin embargo, la SGJN no los considera así. Contundentemente afirma que no son tratados internacionales los acuerdos a que se refiere el artículo 20 en su numerales 7 y 8 .

Ahora bien, ¿qué son y cuál es su fundamento jurídico? En forma interesante, no se basa en la Constitución para encontrar la fundamentación de la naturaleza de esos acuerdos interinstitucionales, 
sino que se remite a la Ley sobre la Celebración de Tratados que establece el fundamento legal ${ }^{29}$.

La SCJN, en dos párrafos (330 y 331) que nos parecen interesantísimos establece su postura frente a lo que se ha llamado la globalización de las relaciones entre entidades no estatales, como se ve en el párrafo 330 que aquí transcribimos:

“330. Sostener que la reserva federal para celebración de tratados internacionales impide que las entidades federativas regulen la posibilidad de celebrar acuerdos de carácter cooperativo y técnico a través de órganos u organismos en particular, sería tanto como desconocer la inserción del México contemporáneo en un mundo globalizado.

Decimos que es interesantísimo porque la Corte se refiere a lo que ella llama "reserva federal para celebración de tratados internacionales", contenida entre otros artículos en el 117 Constitucional, que, subrayemos, es una Constitución del principio del Siglo XX. Bien, ahora la SCJN la interpreta en términos de los fenómenos del siglo XXI. Con eso el más alto tribunal hace una interpretación progresiva de la Constitución, tomándola como una norma viva que se adecúa al momento actual.

Otro párrafo de la sentencia de la SCJN, que nos parece digno de comentar es el siguiente:

“333. Se estima necesario precisar que la Secretaría de Relaciones Exteriores emitió la "Guía para la conclusión de tratados y acuerdos interinstitucionales en el ámbito internacional según la Ley sobre la Celebración de Tratados"235 , que reconoce que los acuerdos inte-

29 "332. Bastan las explicaciones anteriores para evidenciar que, contrario a lo alegado por la Procuraduría, los acuerdos referidos no son tratados internacionales en términos de los artículos 76, fracción I, 89, fracción X, 117, fracción I, y 133 de la Constitución Federal, sino acuerdos interinstitucionales que las entidades federativas están facultadas a suscribir siempre que se apeguen a lo que para tal efecto prevé la Ley sobre la Celebración de Tratados. En esa medida, no existe la invasión de competencias alegada". ACCIÓN DE INCONSTITUCIONALIDAD 15/2017 Y SUS ACUMULADAS 16/2017, 18/2017 Y 19/2017 150. 
rinstitucionales no son tratados internacionales, sino que constituyen la asunción legal de una costumbre o práctica internacional y, para efectos de nuestra materia de análisis, deja claras las cuestiones que pueden ser objeto de suscripción en un acuerdo..."

La SCJN, con su silogismo en el cual incluye a la Ley de Celebración de Tratados, está tomando parte en la discusión sobre la constitucionalidad de los acuerdos interinstitucionales, en dicha ley al considerarlos con esto como constitucionales. Lo cual es interesante, pero se excede al fundamentar su argumentación en una "Guía" que no tiene el pedigrí de una ley y no solo eso, sino que hace suya la afirmación de: "que reconoce que los acuerdos interinstitucionales no son tratados internacionales, sino que constituyen la asunción legal de una costumbre o práctica internacional..."

Técnicamente sabemos que hay una diferencia entre "costumbre" y una simple "practica". Ahora bien, la SCJN asume, sin probarlo, que los acuerdos interinstitucionales son una costumbre, lo que no habla bien de técnica jurídica, pero al final de cuentas es la postura de la SCJN. En efecto, de conformidad con el artículo 38 del Estatuto de la Corte Internacional de Justicia la costumbre internacional es "b. la costumbre internacional como prueba de una práctica generalmente aceptada como derecho".

Aunque la definición anterior no es un modelo de redacción, la doctrina reconoce que la costumbre, para que pueda existir, debe de tener dos elementos; el objetivo (práctica general) y el elemento subjetivo, (aceptada como derecho) o bien, como técnicamente se le conoce como opinio juris. En el caso concreto, a la SCJN no se preocupó de probar la existencia de estos elementos, sino que olímpicamente se basa en una Guía de la Secretaria de Relaciones Exteriores y los considera como costumbre internacional.

En suma, desde la perspectiva de la SCJN, los acuerdos que pudieran ser celebrados por la ciudad de México, de conformidad con el artículo 20 de la CGM no son tratados internacionales, en conse- 
cuencia, no violan lo dispuesto en el artículo 117 de la Constitución Federal. En cambio, son acuerdos interinstitucionales, que es una práctica reconocida como costumbre internacional, La fundamentación de la SCJN está lejos de ser adecuada o mejor dicho nula, aunque pudiera ir por el camino adecuado, pero no es posible probar su afirmación citando una "Guía de la Secretaria de Relaciones Exteriores", que no tiene el rango jurídico adecuado.

VII. Conclusiones

No hay duda de la importancia que tienen los acuerdos internacionales entre organizaciones no estatales. La práctica internacional es muy abundante, no es posible soslayarlos y más con el impulso que la globalización les ha dado. Desde el punto de vista de la doctrina, la figura de los AI tiene dos retos: el primero su definición en el derecho interno y la creación de una estructura que permita tener pesos y contrapesos, controles a una función que puede ser ultra vires y en donde se comprometa al Estado en su totalidad. El ejemplo de la Constitución de la Ciudad de Buenos Aires es interesante y puede ser útil y más en este momento que la CGM carece de normas reglamentarias. Así, independientemente de que la SCJN constitucionaliza la facultad de la Ciudad de México para realizar acuerdos internacionales, que se insiste, no son tratados internacionales, también, constitucionaliza a los acuerdos interinstitucionales que no tienen un soporte constitucional claro.

El segundo reto doctrinal, es la determinación de la naturaleza jurídica de este tipo de acuerdos. Por ahora es claro que estos acuerdos son necesarios, y que son una práctica, pero ¿podemos afirmar que son parte de la costumbre internacional? Supongamos que eso sea claro, desde una simple mirada a la práctica de los Estados, que es copiosa, pero después habría que contestar a una serie de cuestiones, como por ejemplo, ¿quién es el responsable, a nivel inter- 
nacional, por supuesto, por violación de un acuerdo de este tipo?, ¿se aplican las normas de los tratados internacionales a este tipo de acuerdos?, ¿Quién tiene el derecho de acción ante la jurisdicción internacional por el incumplimiento de este tipo de acuerdos?, etcétera. Es todavía una zona gris en la doctrina. Pero por ahora el caso de la CGM es buen ejemplo de la tendencia internacional.

VIII. Fuentes

1. Bibliografía

Arellanes Jiménez, Paulino, Los gobiernos locales de Europa y sus relaciones internacionales, Gernika, México, 2014.

Becerra Ramírez, Manuel, La recepción del derecho internacional en derecho interno, Instituto de Investigaciones Jurídicas, UNAM, México, segunda edición.

Bernal, Carlos, "Los convenios ejecutivos ante el derecho constitucional e internacional”, Jurídica; México, núm. 12, 1980.

Cruz Miramontes, "El tratado de Libre Comercio de América del Norte y las Denominadas 'Cartas paralelas', Anuario Mexicano de Derecho Internacional, México, vol. I, 2001.

Méndez Silva, Ricardo, "La celebración de los tratados genealogía y actualidad constitucional", Anuario Mexicano de Derecho Internacional, México, vol. I, 2001.

Sánchez Reyes, Wendy, ¿Los acuerdos interinstitucionales, constituyen una fuerte de derecho internacional en el siglo XXI?, Tesis de licenciatura, Facultad de Derecho de la Universidad Nacional Autónoma de México, México, 2018.

2. LegISgrafía

AGCIÓN DE INCONSTITUCIONALIDAD 15/2017 Y SUS ACUMULADAS 16/2017, 18/2017 Y 19/2017 150, Suprema Corte de Justicia de la Nación. 
Constitución de la Ciudad Autónoma de Buenos Aires.

Constitución Ecuatoriana.

Constitución Política de la Ciudad de México.

Constitución Política de los Estados Unidos Mexicanos de 1917, D.O.F. 15-.

Constitución Política de la Nación Argentina. 